\title{
Effects of $\gamma$-aminobutyric acid on the tissue structure, antioxidant activity, cell apoptosis, and cytokine contents of bursa of Fabricius in chicks under heat stress
}

\author{
Zhong Chen, Yong-Wei Zhou, Chen Liang, Ying-Ya Jiang, and Li-Jin Xie \\ Ministry of Education Key Laboratory for Tropical Animal and Plant Ecology, \\ Hainan Normal University, Haikou 571158, China
}

Correspondence to: Zhong Chen (zh.chen@hainnu.edu.cn)

Received: 25 October 2015 - Revised: 3 February 2016 - Accepted: 9 February 2016 - Published: 17 February 2016

\begin{abstract}
This study aims to investigate the changes in the tissue structure, cell apoptosis, antioxidant activity, and cytokine contents of the bursa of Fabricius (BF) in chicks under heat stress, and the regulation mechanism of the protective effect of dietary $\gamma$-aminobutyric acid (GABA) on BF in chicks. One-day-old male Wenchang chicks were randomly divided into a control group (CK), heat stress group (HS), and GABA + HS group. The index of BF, area of follicle, density of apoptosis, antioxidant activity (SOD, MDA, and GSH-PX), and cytokine contents (IL-1 $\beta$, IL-6, TNF- $\alpha$, and HSP70) in the BF tissue of chicks were determined at the end of week 1-6. Results showed that HS group had significantly decreased index of BF and area of follicle, and significantly increased density of apoptosis compared with CK group $(P<0.05)$, while GABA + HS group had significantly increased index of BF and area of follicle, and significantly decreased density of apoptosis compared with HS group $(P<0.05)$. There was no significant difference in the total SOD activity in the BF tissue among the three groups, except that GABA + HS group had an increase in total SOD activity in week 6 , which was significantly different from that of CK and HS groups $(P<0.05)$. The GSH-PX activity in the BF tissue was high in all groups in the first 3 weeks, but decreased in week 4-6. The MDA content in the BF tissue of HS and GABA + HS groups was significantly increased compared with that of CK group $(P<0.05)$. There was no significant difference in the HSP70 content between HS and GABA + HS groups $(P>0.05)$, both of which were significantly decreased compared with that of CK group $(P<0.05)$. The contents of IL-1 $\beta$, IL-6, and TNF- $\alpha$ in the BF tissue increased with age in all three groups in week 1-6. In the later BF development, the content of IL-1 $\beta$ in HS group was significantly decreased compared with that of CK group, whereas the content of IL-6 was significantly increased $(P<0.05)$, and no significant difference was observed in the content of TNF- $\alpha$. In contrast, the content of IL-6 in GABA + HS group was significantly decreased compared with that of CK group, and the content of TNF- $\alpha$ was significantly increased $(P<0.05)$. These results suggested that heat stress caused structural damage to the $\mathrm{BF}$ tissue, increased cell apoptosis, and decreased antioxidant activity in the BF of chicks. GABA could alleviate the negative effects of heat stress on the BF tissue and improve the structural and functional development of BF in chicks, by increasing the antioxidant activity, down-regulating IL-6 content, and reducing cell apoptosis in the BF tissue of chicks.
\end{abstract}




\section{Introduction}

With the global warming, the impact of high temperature on animals is of greater concern. Persistent high temperature in summer induces heat stress in animals, leading to their body dysfunction and even death (Sherwood and Huber, 2010). In the poultry industry, domestic birds are susceptible to heat stress because their body is covered with feathers and they lack a sweat gland. Recent studies demonstrated that heat stress causes severe damage to the intestinal tissue structure of chickens and hinders the absorption and utilization of nutrients (Chen et al., 2014, 2015). This leads to reductions in feed intake, feed conversion rate, and body weight of chickens (Mujahid et al., 2005; Niu et al., 2009), which adversely affects the growth of chickens. Moreover, it also has a severe effect on the immune systems of chickens, resulting in weight reduction of the immune organs and weakened antibody response (Bartlett and Smith, 2003).

Bursa of Fabricius (BF) is a specific central immune system organ in poultry where B cells mature and differentiate. The normal development of its physiological function is the premise of the body's immunity (Glick, 1994). If the physiological function of BF is impaired, it affects not only the body's humoral immune reaction but also the physiological function of the whole body. Studies have indicated that in the heat stress conditions, the weight of avian BF is decreased, the lymphocytes in the follicles are reduced, and there is severe vacuolization (Liu et al., 2003; Tarek et al., 2013). Under long-term heat stress, the apoptosis of lymphocytes increases, causing early immunosuppression. Under continuous immunosuppression, the regeneration of lymphocytes in $\mathrm{BF}$ is insufficient to compensate for the damage, which will affect the normal physiological function of the body (Ning et al., 2004). Therefore, it is necessary to study the changes in BF structure and immune function of chickens under heat stress and to investigate the effect of heat stress on the body.

$\gamma$-Aminobutyric acid (GABA) is a functional amino acid widely present in the tissues of animals and plants. As the major inhibitory neurotransmitter in animals, GABA has the effect of stabilization, improving anxiety and functioning as an antidepressant (Leventhal et al., 2003; Mombereau et al., 2004). Currently, GABA has been widely used in food, medicine, and agriculture industries as a new type of functional factor (Akihiro et al., 2008; Schijins et al., 2015; Hu et al., 2015). We have demonstrated in the earlier works that dietary supplementation of GABA can alleviate the damage in the antioxidant system of intestinal mucosa in broiler chickens caused by heat stress and can improve the intestinal digestive enzyme activities (Chen et al., 2013, 2014), which relieves the negative effect of heat stress in broiler chickens and improves the growth of chickens (Chen et al., 2002). In the present study, we aim to investigate the effects of GABA on the structural and functional development of BF in chicks reared under conditions of heat stress, by analyzing the index of BF, area of follicle, antioxidant activity, density of apoptosis, and cytokine levels in chicks.

\section{Materials and methods}

\subsection{Animals and feeding management}

Healthy male Wenchang chickens ( $n=120 ; 1$ day old) obtained from Hainan YongJi Live Stock Co. Ltd, Hainan, China, were used in the study. The birds were weighed, coded, and randomly divided into three groups of 40 birds: control group (CK), heat stress group (HS), and GABA + HS group. There was no significant difference in body weight and feed intake among the groups. The chicks from the CK and HS groups were administered with $0.2 \mathrm{~mL}$ of physiological saline solution daily, while those from the GABA + HS group were administered with $0.2 \mathrm{~mL}$ of $50 \mathrm{mg} \mathrm{kg}^{-1}$ GABA solution (Sigma, USA) daily. Normal feeding was carried out in each group, and chicks were given free access to diets and distilled water. The feeding room $(7 \times 3.5 \times 3.5 \mathrm{~m})$ had natural ventilation and illumination $(\mathrm{L}: \mathrm{D}=14 \mathrm{~h}: 10 \mathrm{~h})$. The test period was 6 weeks. The basic daily diet met the NRC standards (1994), and the chicks in each group were under routine management.

\subsection{Heat stress treatment}

Chicks from HS and GABA + HS groups were subjected to heat stress treatment at $40 \pm 0.5^{\circ} \mathrm{C}$ with a relative humidity of $70-80 \%$ in LRH-800-GS artificial climate chamber (Tomorrow Environmental Protection Instrument Co. LTD, Shaoguan, China) for $2 \mathrm{~h}(13: 00-15: 00 \mathrm{UTC}+8)$ every day. Chicks from CK group were placed in room temperature unit for $2 \mathrm{~h}$ every day. After the treatment, the chicks were put back to the normal breeding cages (Ramnath et al., 2008; Chen et al., 2014).

\subsection{Sample collection}

Six chicks were randomly chosen from each group and sacrificed, at the end of week $1,2,3,4,5$, and 6 . BF was cut out immediately and weighed after the surface connective tissue was removed. A portion of the bursa tissue was fixed by Bouin's fixation fluid for routine paraffin sections. The rest of the tissue was kept at $-20^{\circ} \mathrm{C}$ for tissue homogenate. All procedures used in animal experiments were in compliance with the Hainan Normal University Ethics Committee.

\subsection{Determination of histomorphological index of BF}

\subsubsection{Index of BF}

Body weights of chick were measured at the end of each week. BF tissues were weighed after sacrificed. Index of $\mathrm{BF}$ was calculated as index of BF $\left(\mathrm{g} \mathrm{kg}^{-1}\right)=$ wet weight of $\mathrm{BF} /$ body weight $\times 100 \%$. 
Table 1. Effects of GABA on the histomorphology of the BF in chicks under heat stress.

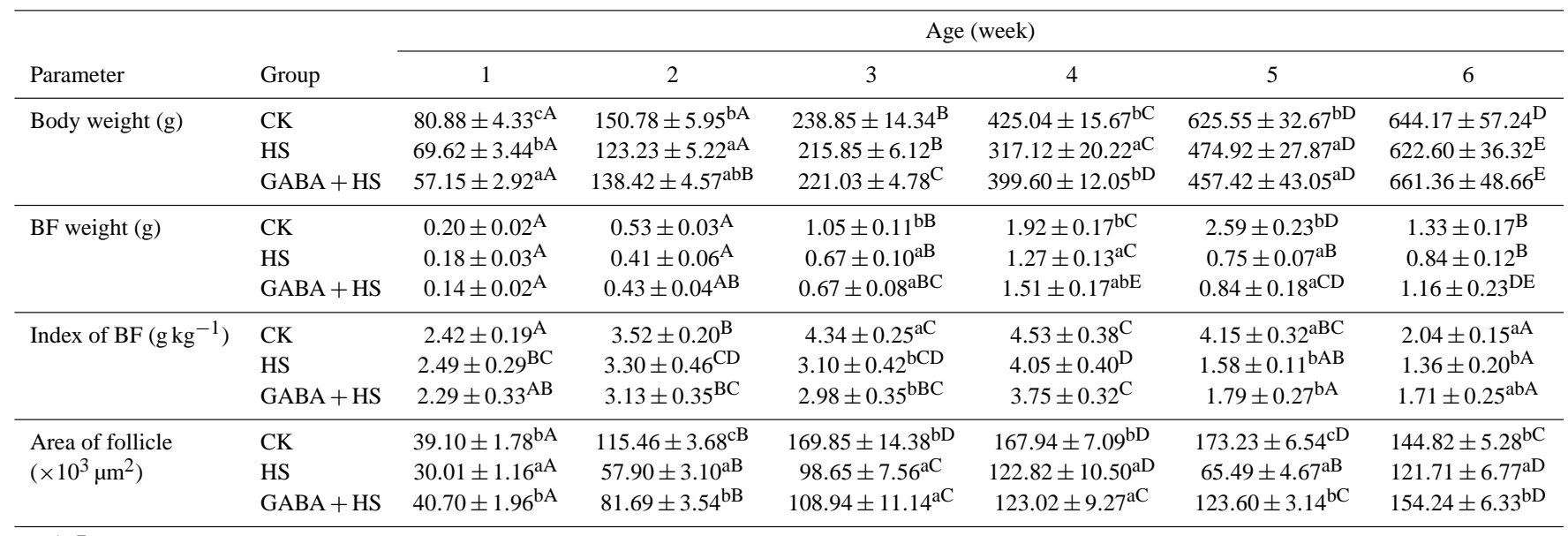

$\mathrm{a}-\mathrm{c}, \mathrm{A}-\mathrm{E}$ Means within a column (lowercase superscripts) or a row (uppercase superscripts) and without a common superscript differ significantly $(P<0.05, n=6)$.

\subsubsection{Area of follicle}

The routine paraffin sections obtained from chicks $(n=6)$ were stained with routine $\mathrm{H}$. E staining. Three tissue sections from each chick and five follicles from each section were randomly chosen for observation of structural change in the BF tissue under microscope. The tissue sections were also photographed with YD400C digital camera (Shangdong Yichuang Electronics Ltd., Jinan, China). Area of follicle was measured by Image-pro Plus 6.0 image analysis software (Media Cybernetics, Inc., USA).

\subsubsection{Cell apoptosis in BF and density of apoptosis}

Experiments were conducted on the routine paraffin sections with TUNEL cell apoptosis detection kit (coloration method) from Nanjing Jiancheng Bioengineering Institute (Nanjing, China) according to the manufacturer's protocol. Three tissue sections were randomly chosen from each sample with five different visual fields for each section and photographed with YD400C digital camera (Shandong Yichuang Electronics Ltd., Jinan, China). The number of apoptotic cells and area of visual field were measured by Image-pro Plus $6.0 \mathrm{im}$ age analysis software (Media Cybernetics, Inc., USA), and the density of apoptosis was obtained by dividing the number of apoptotic cells by the area of visual field.

\subsubsection{Antioxidant activity}

The bursa tissue was washed with ice-cold phosphate buffer saline (PBS) to remove the blood and wiped dry with filter paper. PBS (pH 7.4) was added at a ratio of 9:1 of the tissue weight. The mixture was homogenized with cold glass homogenizer in ice bath, until the cells were completely broken and the color of the liquid was light and uniform. Subsequently, the BF tissue homogenate was centrifuged at $3500 \mathrm{rpm}$ for $10 \mathrm{~min}$ at $4^{\circ} \mathrm{C}$. The supernatant was collected and stored at $-20^{\circ} \mathrm{C}$, for measuring activity of GSH-PX and SOD and MDA content. Measurements were done with reagent kits from Nanjing Jiancheng Bioengineering Institute (Nanjing, China) according to the manufacturer's protocol.

\subsubsection{Cytokine contents}

The contents of IL- $1 \beta$, IL- 6 , TNF- $\alpha$, and HSP70 in the supernatant of $\mathrm{BF}$ tissue homogenate were measured with the ELISA kit for chickens from Shanghai Yu Ping Biotechnology Ltd. Co. (Shanghai, China) according to the manufacturer's protocol. The absorbance (OD value) was measured at $450 \mathrm{~nm}$ wavelength with a microplate reader, and the cytokine levels were calculated based on the standard curve.

\subsection{Statistical analysis}

All data were represented as mean \pm SEM. Experimental data were analyzed using ANOVA with SPSS16.0 software (SPSS Inc, Chicago, US) and using multiple comparisons with Duncan's method. $P<0.05$ was considered statistically significant.

\section{Results}

\subsection{Effect of GABA on the body weight, index of BF, and} BF tissue structure of chicks under heat stress

Table 1 shows that all three groups of chicks gained weight rapidly after 3 weeks of age. In the first week, the body weight of chicks in HS and GABA + HS groups was significantly different from that in CK group $(P<0.05)$. At $2-$ 4 weeks of age, chicks of CK group had the highest body weight, followed by GABA + HS group and HS group. However, there was no significant difference in the body weight of chicks between GABA + HS group and CK group $(P>0.05)$. 


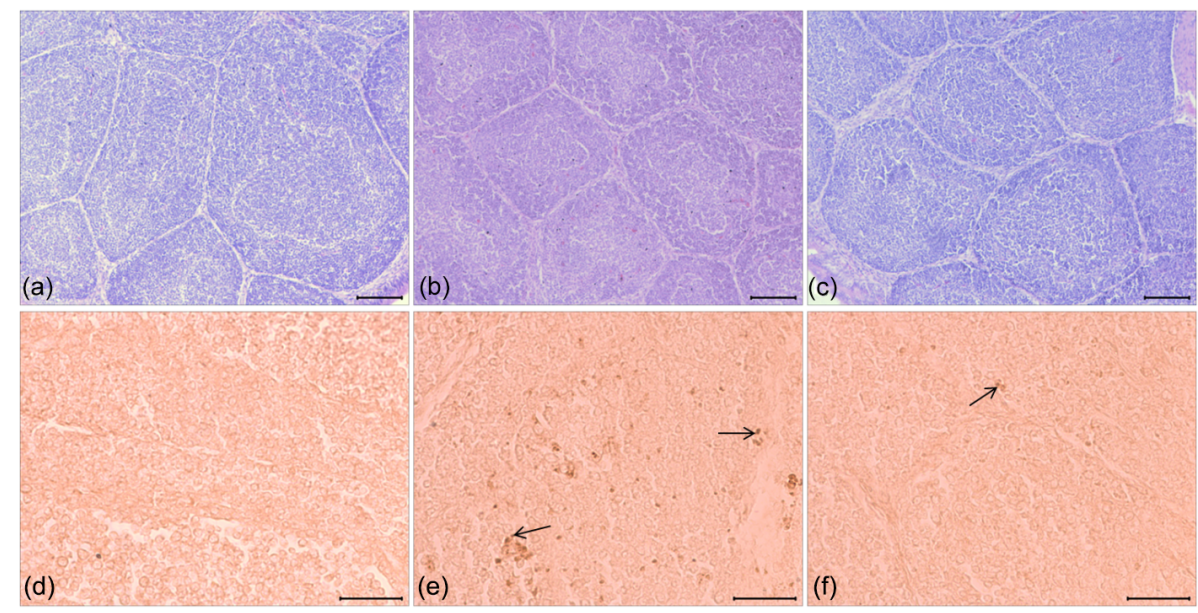

Figure 1. Effects of GABA on the tissue structure and cell apoptosis of the BF in 4-week-old chicks under heat stress. (a-c) The BF tissue structure of chicks, bar $=100 \mu \mathrm{m}$. (d-f) Cell apoptosis in the BF of chicks, bar $=50 \mu \mathrm{m}$. (a, d) Control group; (b, e) HS group; (c, f) GABA + HS group. Arrows: apoptotic cells.

At 6 weeks of age, GABA + HS group had a higher body weight than $\mathrm{CK}$ group.

A significant difference in the index of $\mathrm{BF}$ among the three groups was only observed from 3 weeks of age $(P<0.05)$. The index was highest in CK group, which was consistent with the cumulative growth curve of the chicks. At 3-5 weeks of age, the index of GABA + HS group was not significantly different from that of HS group $(P>0.05)$; while at 6 weeks of age, the index of GABA + HS group was close to that of CK group with no significant difference $(P>0.05)$. The index of BF increased at first and then declined in all groups, and $\mathrm{BF}$ of the Wenchang chicks gradually degenerated after 6 weeks of age (Table 1 ).

Observation of the BF tissue structure in chicks (Fig. 1a-c) showed that HS group had markedly reduced area of follicle, wider follicular space and obvious medullary vacuolization, compared with CK group. Table 1 shows that at 1-2 weeks of age, HS group had the smallest area of follicle, which was significantly different from that of the other two groups $(P<0.05)$. At $3-4$ weeks of age, there was no significant difference in the area of follicle between GABA + HS group and HS group $(P>0.05)$, both of which were significantly different from that of $\mathrm{CK}$ group $(P<0.05)$. At 6 weeks of age, no significant difference was seen in the area of follicle in GABA + HS group when compared to CK group $(P>0.05)$, whereas the smallest area of follicle was seen in HS group with a significant difference from that of the other two groups $(P<0.05)$. Among the three groups of chicks at 1-6 weeks of age, CK group had the largest area of follicle, followed by GABA + HS group and HS group.

\subsection{Effect of GABA on cell apoptosis in the BF tissue of chicks under heat stress}

Table 2 shows that during week 1-6, the density of apoptosis in $\mathrm{CK}$ and GABA + HS groups first increased then declined without significant changes. In contrast, the density of apoptosis increased with age in HS group with a remarkable rise from 2 weeks of age. At 1 and 3 weeks of age, the density of apoptosis in CK group was significantly lower than HS and GABA + HS groups $(P<0.05)$. At $4-6$ weeks of age, there was significant difference in the density of apoptosis among the three groups, with the highest density of apoptosis observed in HS group $(P<0.05)$. At 6 weeks of age, the density of apoptosis in GABA + HS group was close to that of CK group (Fig. 1d-f).

\subsection{Effect of GABA on the antioxidant activity and HSP70 content in the BF tissue of chicks under heat stress}

Figure 2a shows that the total SOD activity in the BF tissue of all groups increased with age. At 6 weeks of age, the total SOD activity of GABA + HS group was significantly higher than that of CK and HS group $(P<0.05)$. Figure $2 \mathrm{~b}$ shows that the GSH-PX activity in the BF tissue was high in all groups in the first 3 weeks, but decreased after 4 weeks of age. At 3 weeks of age, the GSH-PX activity of GABA + HS group was significantly higher than that of CK and HS group $(P<0.05)$. At 5 weeks of age, the GSH-PX activity of HS group was significantly higher than that of CK group $(P<0.05)$. Figure $2 \mathrm{c}$ shows that the MDA content in the BF tissue of HS and GABA + HS groups was higher than that of CK group with a significant difference in week 2, 3, and $6(P<0.05)$. Figure $2 \mathrm{~d}$ shows that the HSP70 content 
Table 2. The effect of GABA on the density of apoptosis in the BF of chicks under heat stress.

\begin{tabular}{lcccccc}
\hline & \multicolumn{5}{c}{ Age (week) } \\
\cline { 2 - 7 } Group & 1 & 2 & 3 & 4 & 5 \\
\hline CK & $21.37 \pm 3.28^{\mathrm{aA}}$ & $31.04 \pm 3.26^{\mathrm{aAB}}$ & $40.77 \pm 4.16^{\mathrm{aB}}$ & $40.49 \pm 4.37^{\mathrm{aB}}$ & $64.91 \pm 8.83^{\mathrm{aC}}$ & $33.38 \pm 2.27^{\mathrm{aAB}}$ \\
HS & $45.41 \pm 4.25^{\mathrm{bA}}$ & $44.13 \pm 5.97^{\mathrm{aA}}$ & $180.35 \pm 11.51^{\mathrm{bB}}$ & $299.45 \pm 27.69^{\mathrm{cC}}$ & $335.43 \pm 14.23^{\mathrm{cC}}$ & $388.52 \pm 35.70^{\mathrm{bD}}$ \\
GABA + HS & $56.7 \pm 4.01^{\mathrm{bA}}$ & $95.69 \pm 8.49^{\mathrm{bA}}$ & $187.48 \pm 21.34^{\mathrm{bB}}$ & $180.01 \pm 21.74^{\mathrm{bB}}$ & $159.15 \pm 24.22^{\mathrm{bB}}$ & $66.51 \pm 5.99^{\mathrm{aA}}$ \\
\hline
\end{tabular}

a-c, A-D Means within a column (lowercase superscripts) or a row (uppercase superscripts) and without a common superscript differ significantly $\left(P<0.05, \times 10^{-5} \mu \mathrm{m}^{-2}, n=6\right)$

(a)

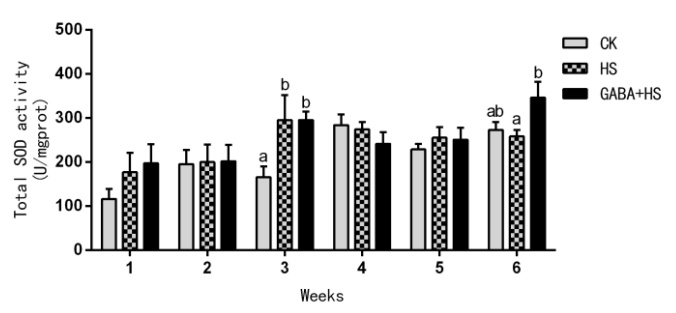

(c)

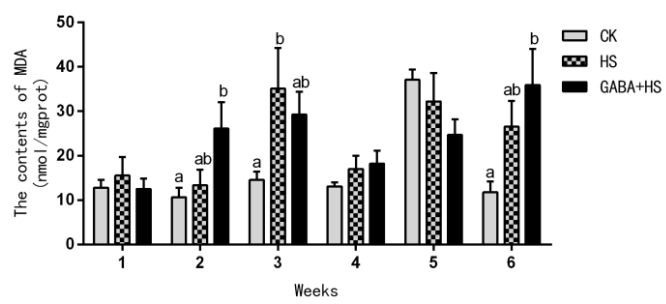

(b)

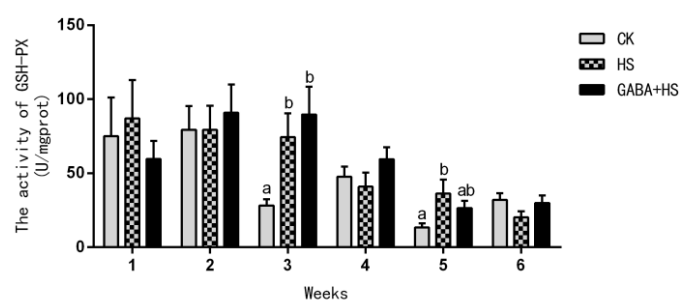

(d)

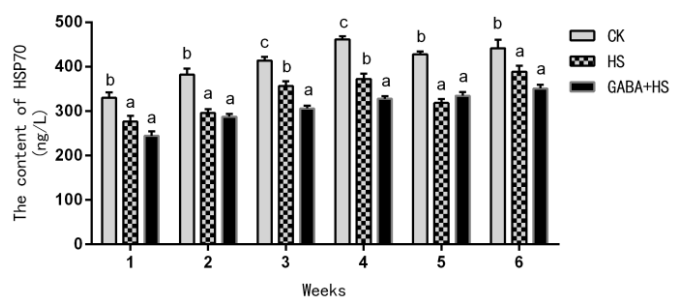

Figure 2. Effects of GABA on the activity of SOD and GSH-PX and the content of MDA and HSP70 in the BF of chicks under heat stress $(n=6)$. (a) The change of total SOD activity in the BF of chicks under heat stress. (b) The change of GSH-PX activity in the BF of chicks under heat stress. (c) The change of MDA content in the BF of chicks under heat stress. (d) The change of HSP70 content in the BF of chicks under heat stress.

in the BF tissue of HS and GABA + HS groups was significantly lower than that of CK group $(P<0.05)$ in week $1-6$.

\subsection{Effects of GABA on the cytokine level in BF of chicks under heat stress}

Table 3 shows that the content of IL- $1 \beta$ in BF increased with age in all three groups in week 1-6. At 1 week of age, HS group had the highest content of IL-1 $\beta(P<0.05)$. At $2-$ 3 weeks of age, there was no significant difference in the content of IL- $1 \beta$ among the three groups $(P>0.05)$. At $4-$ 6 weeks of age, CK group had the highest content of IL-1 $\beta$ $(P<0.05)$. Compared with $\mathrm{CK}$ group, the content of IL-1 $\beta$ in BF of HS group was significantly different in week 1 and 4 only $(P<0.05)$. The content of IL-6 in BF increased with age in all three groups in week 1-6. The content of IL-6 in HS group was significantly increased compared with that in CK group $(P<0.05)$. The content of IL-6 in GABA + HS group was significantly decreased compared with that in the other two groups $(P<0.05)$. The content of TNF- $\alpha$ in BF of GABA + HS group was significantly increased compared with that of $\mathrm{CK}$ and HS groups in all weeks $(P<0.05)$.

\section{Discussion}

Wenchang chicks were reported to gain body weight slowly in the first 3 weeks and enter a rapid growth stage after that (Zhou et al., 2015). In this study, we found that at 3-4 weeks of age, chicks of CK group had the highest body weight, followed by GABA + HS group and HS group. This was possibly because the internal organs of the chicks were in a rapid growth stage after 3 weeks; however, the body of chicks in $\mathrm{HS}$ and GABA + HS groups consumed more energy to compensate for the cumulative damage induced by heat stress, instead of growth. As a result, the weight gain of these two 
Table 3. Effects of GABA on the contents of IL- $1 \beta$, IL-6, and TNF- $\alpha$ in the BF of chicks under heat stress.

\begin{tabular}{|c|c|c|c|c|c|c|c|}
\hline \multirow{2}{*}{$\begin{array}{l}\text { Parameter } \\
\left(\text { ng L }^{-1}\right)\end{array}$} & \multirow[b]{2}{*}{ Group } & \multicolumn{6}{|c|}{ Age (week) } \\
\hline & & 1 & 2 & 3 & 4 & 5 & 6 \\
\hline \multirow[t]{3}{*}{$\mathrm{IL}-1 \beta$} & CK & $76.61 \pm 3.87^{\mathrm{aA}}$ & $106.71 \pm 4.83^{\mathrm{B}}$ & $109.88 \pm 3.03^{\mathrm{B}}$ & $133.63 \pm 2.93^{\mathrm{bCD}}$ & $126.65 \pm 2.86^{\mathrm{bC}}$ & $138.08 \pm 2.67^{\mathrm{bD}}$ \\
\hline & HS & $97.06 \pm 4.14^{\mathrm{bA}}$ & $109.50 \pm 4.45^{\mathrm{B}}$ & $120.42 \pm 3.30^{\mathrm{C}}$ & $121.44 \pm 3.41^{\mathrm{aC}}$ & $118.14 \pm 1.71^{\mathrm{abBC}}$ & $134.14 \pm 2.50^{\mathrm{bD}}$ \\
\hline & $\mathrm{GABA}+\mathrm{HS}$ & $80.20 \pm 2.73^{\mathrm{Aa}}$ & $97.65 \pm 2.17^{\mathrm{B}}$ & $109.41 \pm 4.45^{\mathrm{BC}}$ & $113.12 \pm 4.74^{\mathrm{aC}}$ & $112.86 \pm 6.05^{\mathrm{aC}}$ & $118.91 \pm 4.06^{\mathrm{aC}}$ \\
\hline \multirow[t]{3}{*}{ IL-6 } & CK & $20.47 \pm 0.82^{\mathrm{bA}}$ & $26.53 \pm 1.74^{\mathrm{bB}}$ & $31.17 \pm 0.90^{\mathrm{bC}}$ & $33.55 \pm 0.64^{\mathrm{bCD}}$ & $33.79 \pm 1.55^{\mathrm{bCD}}$ & $36.97 \pm 1.34^{\mathrm{bD}}$ \\
\hline & HS & $25.09 \pm 0.31^{\mathrm{cA}}$ & $31.50 \pm 1.26^{\mathrm{cB}}$ & $38.43 \pm 1.60^{\mathrm{cC}}$ & $39.57 \pm 0.96^{\mathrm{cC}}$ & $38.17 \pm 0.85^{\mathrm{cC}}$ & $44.73 \pm 1.43^{\mathrm{cD}}$ \\
\hline & $\mathrm{GABA}+\mathrm{HS}$ & $17.89 \pm 0.52^{\mathrm{aA}}$ & $22.27 \pm 0.51^{\mathrm{aB}}$ & $22.10 \pm 0.52^{\mathrm{aB}}$ & $24.43 \pm 0.60^{\mathrm{aC}}$ & $25.06 \pm 0.47^{\mathrm{aC}}$ & $25.16 \pm 0.66^{\mathrm{aC}}$ \\
\hline \multirow[t]{3}{*}{ TNF- $\alpha$} & $\mathrm{CK}$ & $59.48 \pm 1.04^{\mathrm{aA}}$ & $67.08 \pm 1.98^{\mathrm{aB}}$ & $70.92 \pm 1.13^{\mathrm{aB}}$ & $77.22 \pm 0.94^{\mathrm{aC}}$ & $77.25 \pm 1.24^{\mathrm{aC}}$ & $80.95 \pm 1.44^{\mathrm{aC}}$ \\
\hline & HS & $62.76 \pm 0.94^{\mathrm{aA}}$ & $69.68 \pm 2.21^{\mathrm{aB}}$ & $71.82 \pm 1.03^{\mathrm{aBC}}$ & $76.31 \pm 1.85^{\mathrm{aD}}$ & $75.35 \pm 1.23^{\mathrm{aCD}}$ & $82.05 \pm 0.87^{\mathrm{aE}}$ \\
\hline & $\mathrm{GABA}+\mathrm{HS}$ & $78.34 \pm 4.80^{\mathrm{bA}}$ & $98.85 \pm 2.06^{\mathrm{bB}}$ & $95.88 \pm 1.6^{\mathrm{bB}}$ & $97.26 \pm 1.76^{\mathrm{bB}}$ & $98.11 \pm 1.89^{\mathrm{bB}}$ & $94.40 \pm 1.70^{\mathrm{bB}}$ \\
\hline
\end{tabular}

a-c, A-D Means within a column (lowercase superscripts) or a row (uppercase superscripts) and without a common superscript differ significantly $(P<0.05, n=6)$.

groups was less than that of CK group. GABA + HS group had a higher body weight than HS group, suggesting that the addition of GABA might alleviate part of the damage caused by heat stress, and therefore the body weight of GABA + HS group was close to or higher than that of CK group.

We found that in week $1-6$, the index of BF in all three groups of Wenchang chicks had a downward trend after the first increase. The index of BF in white Leghorn chicks has also been reported with the similar trend at 1-60 days of age (Zhang et al., 2006; Tang and Chen, 2015). Mashaly et al. (2004) also reported that heat stress inhibited the total white blood cell counts and antibody production in commercial laying hens, and lymphocytes of heat-stressed hens had the least activity at 1 week following treatment. This might be related to the gradual degradation of BF function due to the maturation of B lymphocytes in BF and their migration to the peripheral tissues and organs at this stage. In the early several weeks, there was no significant difference in the index of BF among the three groups, and significant difference was only seen in week 5-6, likely because the difference in the index of BF among the groups was not obvious in the initial stage of BF development with a slow body weight gain. At 5-6 weeks of age, the BF tissues of HS and GABA + HS groups are incompletely developed due to the cumulative attack of heat stress, and the damage caused by heat stress is more severe in the BF tissue than in other tissues (Tarek et al., 2013). Therefore, the index of BF in these two groups was lower than that of CK group. GABA + HS group showed an index of BF higher than HS group and close to CK group, implying the alleviation effect of GABA. However, Santin et al. (2003) reported that NDV and IBDV antibody titers in broiler chicks under three different temperatures $\left(18 \pm 2,24 \pm 2\right.$, and $\left.32 \pm 2{ }^{\circ} \mathrm{C}\right)$ were not significantly different $(P>0.05)$. This was probably due to the different high temperatures tested $\left(32\right.$ vs. $\left.40^{\circ} \mathrm{C}\right)$.

Follicle development is the basis of BF development; hence, the development of BF can be reflected to a certain extent by measuring the area of follicle. We found that HS group had the smallest area of follicle in BF compared with CK group in week 1-6. Oznurlu et al. (2010) also reported that the development of thymus and $\mathrm{BF}$ in chicks from heat stressed eggs (exposed continuously to $38.8^{\circ} \mathrm{C}$ from 10 th day of incubation) was retarded, and the lymphocyte levels of heat-stressed animals were lower than in the controls. This could be attributed to the follicular dysplasia of HS group starting from the first week due to the damage in BF caused by heat stress. In contrast, the area of follicle in GABA + HS group was not statistically different from that in CK group in the first week, possibly because the damage caused by heat stress was not sufficient to affect the normal development of BF follicles under the action of GABA. However, in week 2-5, the area of follicle in GABA + HS group could not return to normal due to the cumulative damage induced by heat stress, which was the most severe in week 3 and 4 for both HS and GABA + HS groups. It was possibly because this was the rapid development period of the $\mathrm{BF}$ follicles that requires a large amount of energy. However, due to the accumulation of heat stress, the body had to consume excessive energy to alleviate heat stress-induced damage instead of using the energy for development. In week 6 , the area of follicle in GABA + HS group was close to that in CK group, possibly because the long-term action of GABA alleviated the heatstress-induced damage and allowed the recovery of follicular development. This was in accordance with the changes in the index of BF.

Cell apoptosis is an important life phenomenon in multicellular organisms, which plays an essential role in the normal development of the organism. In week 1-6, the apoptosis of BF cells in CK group first increased then declined without significant change. The density of apoptosis reached the maximum in week 5 and returned to the level of week 2 in week 6 . A possible reason is that the development of BF was the most vigorous in week 5 , so the number of natural apoptotic cells also increased. The decrease in cell apoptosis in 
week 6 might be associated with the slow-down development and gradual degeneration of BF during the period, which was consistent with the trend of change in the index of $\mathrm{BF}$ and area of follicle. The BF cell apoptosis in HS group was at a low level in week 1 and 2 but increased remarkably in week 3-6. A possible explanation could be that the damage caused by heat stress was not sufficient to cause disturbance of apoptosis in the first 2 weeks. However, from week 3, the rapid growth of chicks and accumulation of heat stress in BF resulted in a substantial increase in the apoptosis of BF cells. GABA + HS group had a high level of BF cell apoptosis in week 3 , which gradually decreased after that and was close to that of CK group in week 6. This could be attributed to the alleviation of heat stress by GABA.

An oxidant-antioxidant system is present in normal organisms, the homeostasis of which maintains the normal development of tissues. Studies have indicated that the body can produce reactive oxygen species under heat stress (Khar et al., 2006; Del Vesco and Gasparino, 2013), and the antioxidant activity of tissues can be determined by measuring the activity of SOD and GSH-PX, and MDA content in tissues (Wang et al., 2008; Starrs et al., 2001). In this study, we found a significant difference in the total SOD activity in the BF tissue among the three groups in week 3 and 6 only. In week 3, the total SOD activity in the BF tissue of HS and GABA + HS groups was higher than that of CK group, because the BF tissue of HS and GABA + HS groups was under the heat attack in week 3 , leading to excessive production of reactive oxygen species in BF cells. As a result, the body upregulated the SOD activity by a compensatory mechanism in order to maintain the oxidant-antioxidant balance in the BF tissue. In week 6, the total SOD activity in the BF tissue of GABA + HS group was higher than that of CK and HS groups, possibly because of long-term addition of GABA, which increased SOD activity and therefore the antioxidant capacity of the BF tissue in chicks (Chen et al., 2013).

The GSH-PX activity of all groups was high in the first 3 weeks but became relatively low after week 4 . Since rapid growth of chicks occurred after 3 weeks, it was speculated that GSH-PX had a great effect on the early development of BF tissue in chicks. The decreased GSH-PX activity in week 4-6 might be related to the degeneration of BF in chicks. In addition, the content of MDA in BF tissue of both HS and GABA + HS groups was higher than that in CK group from week 2. It suggested that the BF tissue was damaged by cumulative heat stress, leading to excessive production of MDA in BF cells; GABA did not effectively remove MDA in the BF tissue. This was in disagreement with the view that GABA can significantly remove MDA in intestinal tissues of chickens (Chen et al., 2013). It might be related to the dose of GABA to produce the effect, as it was easier for GABA to get into the small intestine than the BF tissue with the same dose of GABA administered.

HSP70 is a member of the heat shock protein family, the content of which increases significantly under stress. There- fore, the content of HSP70 is often used as a specific indicator of stress. Zulkifli et al. (2000) found that early age feeding restriction may improve heat tolerance in female broiler chickens from 35 to 41 days of age during which all birds were exposed to $38^{\circ}$ for $2 \mathrm{~h} \mathrm{day}^{-1}$. The results indicate that the $60 \%$ feed restriction was beneficial for alleviating the detrimental effects of heat stress in female broiler chickens. This experiment implied that the $60 \%$ feed restriction at 4, 5, and 6 days of age, a mild stressor, may enhance the formation of heat shock proteins for resistance to $38^{\circ}$ ambient temperature in female broiler chickens. However, our results showed that the content of HSP70 in both HS and $\mathrm{GABA}+\mathrm{HS}$ groups was lower than that of $\mathrm{CK}$ group in week 1-6, and there was no significant difference between GABA + HS group and HS group. This was similar to the finding reported by Zhou et al. (2010), who found that the expression level of HSP70 decreased significantly in the spleen of laying ducks with longer period of heat stress. A possible explanation is that the damage in the BF tissue caused by cumulative heat stress was too severe, and the ability of chicks to synthesize HSP70 in this period was insufficient, leading to impeded synthesis and secretion of HSP70 in the BF tissue. Besides, the effect of GABA to relieve heat stress was insufficient to offset the impaired synthesis of HSP70 in chicks caused by heat stress, resulting in the insignificant difference in HSP70 content between GABA + HS group and HS group. It will be more interesting whether the $60 \%$ feed restriction and GABA co-feeding may alleviate significantly the detrimental effects of heat stress.

Abnormalities in metabolism and endocrine in animals induced by stress, which will lead to reduced growth and impaired immunity, were caused by the inhibitory effect of inflammatory cytokines such as IL- $1 \beta$, IL-6, and TNF- $\alpha$ (Johnson, 1997). In this study, we found a significant increase in the content of IL-6 in the BF tissue of HS group compared with that of CK group and no significant change in the content of TNF- $\alpha$. In contrast, GABA + HS group showed a significantly decreased content of IL- 6 and a significant increased content of TNF- $\alpha$ in the BF tissue, compared with CK group. It suggested that heat stress caused increased production of IL- 6 in the BF tissue of chicks, which hindered the development of BF. This was consistent with the earlier studies that reported stress causes a significant increase in the contents of IL- 6 and TNF- $\alpha$ in the plasma of piglets and serum of layers (Webel et al., 1997; Gao et al., 2006). GABA alleviated the damage in BF of chicks caused by heat stress through inhibiting the level of IL-6 in the BF. However, it was hard to explain why the content of $\mathrm{TNF}-\alpha$ remained unchanged in HS group, and was significantly increased in GABA + HS group. We suspected that it might be related to the different tissue studied and dose of GABA received by the BF tissue, which would be the focus of our future investigation. 


\section{Conclusions}

Heat stress hindered the structural development of BF tissue in chicks and caused increased cell apoptosis, decreased antioxidant activity, and imbalance of cytokine secretion in $\mathrm{BF}$, which adversely affected the functional development of BF in chicks. We demonstrated that GABA could be used as an additive to alleviate the negative effects of heat stress on the tissue structure and functional development of BF in chicks, and to improve the internal environment of heatstressed chicks for the normal development of BF.

Acknowledgements. This study was supported by National Natural Science Foundation of China under grants NSFC 31260555 and 31560680 .

Edited by: M. Mielenz

Reviewed by: two anonymous referees

\section{References}

Akihiro, T., Koike, S., Tani, R., Tominaga, T., Watanabe, S., Iijima, Y., Aoki, K., Shibata, D., Ashihara, H., Matsukura, C., Akama, K., Fujimuna, T., and Ezura, H.: Biochemical mechanism on GABA accumulation during fruit development in tomato, Plant. Cell. Physiol., 49, 1378-1389, 2008.

Bartlett, J. R. and Smith, M. O.: Effects of different levels of zinc on the performance and immunocompetence of broilers under heat stress, Poultry Sci., 82, 1580-1588, 2003.

Chen, Z., Wang, T., Huang, L. M., and Fang, D. N.: Effects of GABA on the heat stress broilers, Zool. Res., 23, 341-344, 2002 (in Chinese).

Chen, Z., Tang, J., Sun, Y. Q., and Xie, J.: Protective effect of $\gamma$ aminobutyric acid on antioxidation function in intestinal mucosa of wenchang chicken induced by heat stress, J. Anim. Plant. Sci., 23, 1634-1641, 2013.

Chen, Z., Xie, J., Wang, B., and Tang, J.: Effect of $\gamma$-aminobutyric acid on digestive enzymes, absorption function, and immune function of intestinal mucosa in heat-stressed chicken, Poultry Sci., 93, 2490-2500, 2014.

Chen, Z., Xie, J., Hu, M. Y., Tang, J., Shao, Z. F., and Li, M. H.: Protective effects of $\gamma$-aminobutyric acid (GABA) on the small intestinal mucosa in heat-stressed Wenchang chicken, J. Anim. Plant. Sci., 25, 78-87, 2015.

Del Vesco, A. P. and Gasparino, E.: Production of reactive oxygen species gene expression, and enzymatic activity in quail subjected to acute heat stress, J. Anim. Sci., 91, 582-578, 2013.

Gao, Y. Y., Li, H. B., Jiang, Y. F., Lei, J. M., Pan, Y. F., Huang, J. W., and Ma, Q. M.: Effects of CLA on layer immunity function under heat stress models - Part II: changes of cell factor, hormone level, anti-oxidized ability, J. Northwest A\&F Univ., 34, 1-5, 2006 (in Chinese).

Glick, B.: The Bursa of Fabricius: the evolution of a discovery, Poultry Sci., 73, 979-983, 1994.

Hu, H., Bai, X., Shah, A. A., Wen, A. Y., Hua, J. L., Che, C. Y., He, S. J., Jiang, J. P., Cai, Z. H., and Dai, S. F.: Dietary supplementation with glutamine and $\gamma$-aminobutyric acid improves growth performance and serum parameters in 22- to 35-day-old broilers exposed to hot environment, J. Anim. Phys. Anim. Nut., doi:10.1111/jpn.12346, online first, 2015.

Johnson, R. W.: Inhibition of Growth by Pro-Inflammatory Cytokines: An Integrated View, J. Anim. Sci., 75, 1244-1255, 1997.

Khar, A., Kumari, A. L., Pardhasaradhi, B. W., Varalakshmi, C., and Rangaraj, N.: Heat stress induced apoptosis in BC-8 cells derived from AK-5 tumor involves down regulation of Bcl-2 and generation of reactive oxygen species, India J. Exp. Bio., 44, 802-808, 2006.

Leventhal, A. G., Wang, Y., Pu, M., Zhou, Y. F., and Ma, Y. Y.: GABA and its agonists improved visual cortical function in senescent monkeys, Science, 300, 812-815, 2003.

Liu, S. D., Ning, Z. Y., Tan, X., and Wang, S. Y.: The effect of heatstress on the immune system of Broiler, Chinese J. Vet. Sci., 23, 281-283, 2003 (in Chinese).

Mashaly, M. M., Hendricks, G. L., Kalama, M. A., Gehad, A. E., Abbas, A. O., and Patterson, P. H.: Effect of heat stress on production parameters and immune responses of commercial laying hens, Poultry Sci., 83, 889-894, 2004.

Mombereau, C., Kaupmann, K., Froestl, W., Sansiq, G., van der Putten, H., and Cryan, J. F.: Genetic and pharmacological evidence of a role for GABA(B) receptors in the modulation of anxiety-and antidepressant-like behavior, Neuropsychopharmacology, 29, 1050-1062, 2004.

Mujahid, A., Yoshiki, Y., Akiba, Y., and Toyomizu, M.: Superoxide radical production in chicken skeletal muscle induced by acute heat stress, Poultry Sci., 84, 307-314, 2005.

Ning, Z. Y., Liu, S. D., Zhao, D. M., Hao, J. F., Yang, J. M., and Qin, X. H.: Observations on Ultra Structure and Assaying Apoptotic Cells of Thymus and Bursa of Fabricius in the Experimental Heat-Stressed Broilers, Chinese J. Anim. Vet. Sci., 35, 310-313, 2004 (in Chinese).

Niu, Z. Y., Liu, F. Z., Yan, Q. L., and Li, W. C.: Effects of different levels of vitamin $\mathrm{E}$ on growth performance and immune responses of broilers under heat stress, Poultry Sci., 88, 21012107, 2009.

Oznurlu, Y., Celik, I., Telatar, T., and Sur, E.: Histochemical and histological evaluations of the effects of high incubation temperature on embryonic development of thymus and bursa of Fabricius in broiler chickens, British poultry sci., 51, 43-51, 2010.

Ramnath, V., Rekha, P. S., and Sujatha, K. S.: Amelioration of heat stress induced disturbances of antioxidant defense system in chicken by Brahma Rasayana, Evidence-Based Compl. Alt. Med., 5, 77-84, 2008.

Santin, E., Maiorka, A., Polveiro, W. J. C., Paulillo, A. C., Laurentiz, A. C., Borges, S. A., and da Silva, A. F.: Effect of environmental temperature on immune response of broilers, J. App. Poultry Res., 12, 247-250, 2003.

Schijins, O., Karaca, Ü., Andrade, P., Nijs, L., Küsters, B., Peeters, A., Dings, J., Pannek, H., Ebner, A., Rijkers, K., and Hoogland, G.: Hippocampal GABA transporter distribution in patients with temporal lobe epilepsy and hippocampal sclerosis, J. Chem. Neuroanatomy, 68, 39-44, 2015.

Sherwood, S. C. and Huber, M.: An adaptability limit to climate change due to heat stress, PNAS, 107, 9552-9555, 2010.

Starrs, A. P., Orgeig, S., Daniels, C. B., Davies, M., and Lopatko, O. V.: Antioxidant enzymes in the developing lungs of egg-laying 
and metamorphosing vertebrates, J. Exp. Bio., 204, 3973-3981, 2001.

Tang, J. and Chen, Z.: The protective effect of $\gamma$-aminobutyric acid on the development of immune function in chickens under heat stress, J. Anim. Phys. Anim. Nut., doi:10.1111/jpn.12385, online first, 2015.

Tarek, K., Mohamed, M., Hassina, B., and Messaouda, I.: Histological Study of the Bursa of Fabricius of Broiler Chickens During Heat Stress, Int. J. Poultry Sci., 12, 377-378, 2013.

Wang, L., Piao, X. L., Kim, S. W., Piao, X. S., Shen, Y. B., and Lee, H. S.: Effects of Forsythia suspense extract on growth performance, nutrient digestibility, and antioxidant activities in Broiler Chickens under high ambient temperature, Poultry Sci., 87, 1287-1294, 2008.

Webel, D. M., Finck, B. N., Baker, D. H., and Johnson, R. W.: Time course of increased plasma cytokines, cortisol, and urea nitrogen in pigs following intraperitoneal injection of lipopolysaccharide, J. Anim. Sci., 75, 1514-1520, 1997.
Zhang, H. M., Hunt, H. D., Kulkarni, G. B., Palmquist, D. E., and Bacon, L. D.: Lymphoid Organ Size Varies Among Inbred Lines $6_{3}$ and $7_{2}$ and Their Thirteen Recombinant Congenic Strains of Chickens with the Same Major Histocompatibility Complex, Poultry Sci., 85, 844-853, 2006.

Zhou, L. L., Tao, Z. R., Zhang, C., Li, G. Q., Shen, J. D., Ren, J. D., Shi, F. X., and Lu, L. Z.: Effects of Acute Heat Stress on the Expression Levels of HSP70 Gene in Duck Spleens, Gen. Breeding, 46, 6-9, 2010.

Zhou, Y. W., Cai, T., Zou, H. J., and Chen, Z.: Study on Weight, Visceral Organs Development and Heart Rate Variation in Male Wenchang chicks, J. Dom. Anim. Eco., 36, 39-43, 2015 (in Chinese).

Zulkifli, I., Norma, M. C., Israf, D. A., and Omar, A. R.: The effect of early age feed restriction on subsequent response to high environmental temperatures in female broiler chickens, Poultry Sci., 79, 1401-1407, 2000. 